\title{
RUTE OPTIMAL KENDARAAN BERMOTOR BERDASARKAN KETERJANGKUAN RUMAH SAKIT UMUM DI KOTA YOGYAKARTA
}

\author{
Oleh: \\ Zen Muttaqin dan Nurhadi \\ Jurusan Pendidikan Geografi FIS UNY \\ Zenmuttaqin94@gmail.com
}

\begin{abstract}
Abstrak
Tujuan dari penelitian ini: (1) mengidentifikasi keterjangkauan masing- masing rumah sakit umum di Kota Yogyakarta, (2) menganalisis rute optimal yang dilalui masyarakat untuk menuju rumah sakit umum. Metode yang digunakan menggunakan analisis deskriptif kuantitatif dengan memanfaatkan network analysis pada Sistem Informasi Geografis. Wawancara pada key person dilakukan untuk mengetahui persebaran dari keterjangkauan rumah sakit. Variabel penelitian ini adalah: karakteristik hambatan lalulintas seperti kepadatan lalu lintas, trafficlight, jalan satu arah dan dua arah, perlintasan rel kereta api; jarak tempuh; waktu tempuh. Hasil yang didapatkan adalah masing-masing rumah sakit umum memiliki keterjangkauan berbeda-beda dalam pelayanannya. Hal ini dikarenakan keterjangkauan pada teori fasilitas pelayanan hanya menjangkau pada jumlah penduduk. Rumah sakit yang memiliki jangkauan terluas adalah Rumah Sakit Ludira Husada Tama, meliputi Kecamatan Jetis, Kecamatan Tegalrejo, Kecamatan Gedongtengen, dan Kecamatan Wirobrajan. Rute optimal yang didapatkan dari hasil network analysis memilih lokasi rumah sakit yang berada di dekatnya dengan jangkauan lima hingga sepuluh menit tergantung pada jumlah hambatan, panjang jalan, dan kepadatan lalu lintas yang dilalui. Rute tercepat dapat dilakukan melalui Kecamatan Danurejan menuju Rumah Sakit Bethesda Lempuyangwangi dengan waktu tempuh kurang dari satu menit.
\end{abstract}

Kata kunci: Rumah Sakit, SIG, Network Analysis, Keterjangkauan, Kota Yogyakarta

\begin{abstract}
The objectives of this research are: (1) identifying the affordability of each public hospital in the city of Yogyakarta, (2) analyzing the best route through which the people go to public hospitals. This research uses quantitative descriptive analysis method employing a network analysis in Geographic Information System (GIS). Interviews to the key persons aim at determining the distribution of hospital affordability. Variables in this research include the characteristics of the traffic obstacles such as traffic density, traffic light, one way and two-way street, rail road; distance, travel time. The findings show that general hospitals have different affordability in its service. This is because affordability based on the theory of service facilities only cover the population. The hospital which has widest reach is Ludira Husada Tama Hospital, covering Jetis District, Tegalrejo District, Gedongtengen District, and Wirobrajan District. The best route based on the network analysis is nearby hospitals which take five to ten minutes depending on the number of obstacles such as longroad, and traffic. The quickest route can be reached through Danurejan District to Bethesda Lempuyangwangi Hospital which takes less than one minute.
\end{abstract}

Keywords: Hospital, Geographic Information System, Network Analysis, Affordability, Yogyakarta City 


\section{PENDAHULUAN}

Transportasi memiliki peranan penting dalam kehidupan manusia (Sasmita, 2011:8). Peranan ini terdiri dari pengangkutan dan perpindahan dari satu tempat ke tempat yang lainnya. Perpindahan yang dilakukan oleh manusia memiliki tujuan yang berbeda-beda seperti untuk bekerja, wisata, pendidikan, dan lain-lain. Secara tidak langsung, layanan transportasi memiliki manfaat yang dimanfaatkan oleh sistem kota dalam menentukan pola jaringan berdasarkan fungsi-fungsi tertentu. Sistem perkotaan yang ideal memiliki sistem transportasi yang baik seperti sistem yang ada di Kota Yogyakarta. Selain sistem transportasi yang baik, daya tarik perkotaan juga ditentukan oleh adanya fungsi dari fasilitas pelayanan. Kondisi inilah yang menyebabkan pertambahan jumlah penduduk yang signifikan di Kota Yogyakarta. Berdasarkan data Daerah dalam Angka menunjukkan bahwa dari tahun 2008 hingga 2013 kepadatan penduduk dan jumlah penduduk Kota Yogyakarta mengalami peningkatan dari 12.024 menjadi 12.391 dengan luas $32,5 \mathrm{~km}^{2}$, sedangkan jumlah penduduk mengalami peningkatan dari 390.783 menjadi 402.709 jiwa (BPS, 2014).

Tingginya jumlah penduduk yang tidak diimbangi dengan sistem jaringan jalan menimbulkan permasalahan baru seperti kejenuhan lalu lintas hingga kemacetan. Kondisi ini diperparah dengan rekayasa lalu lintas yang justru dapat semakin memperlambat waktu tempuh. Disisi lain, kebutuhan masyarakat akan fasilitas penunjang seperti transportasi akan memicu permasalahan lain seperti banyaknya kecelakaan lalu lintas. Seperti halnya kecelakaan lalu lintas, permasalahan lain yang memerlukan penanganan cepat adalah permasalahan kesehatan. Hal ini disebabkan keterlambatan dalam penanganan saat terjadi kecelakaan atau keadaan darurat dapat menyebabkan hilangnya nyawa seseorang.

Peningkatan volume kendaraan dan tidak bertambahnya ruas jalan serta tingginya kebutuhan akan fasilitas pelayanan kesehatan dapat memperburuk pelaksaan kegiatan transportasi. Dibutuhkan cara yang cepat untuk dapat memperoleh rute optimal fasilitas kesehatan seperti menuju rumah sakit umum. Rute optimal menuju rumah sakit ditentukan atas beberapa faktor salah satunya adalah faktor lokasi (ESRI, 2012). Lokasi ini akan memberikan penjelasan lebih jauh tentang tempat atau daerah yang bersangkutan (Sumaatmadja,1981:118). Penjelasan lebih lanjut mengenai teori lokasi dikemukaan oleh Walter Christaller pada tahun 1933. Teori ini lebih memperhatikan terhadap penyebaran pemukiman, desa, kota-kota yang berbeda-beda ukuran luasnya, atas dasar lokasi dan penyebaran pemukiman dalam ruang itulah Christaller mengemukaan teori tersebut (Sumaatmadja, 1981:121). Implikasi yang ditimbulkan dengan adanya teori lokasi meliputi keterjangkauan dari rumah sakit umum untuk dapat melayani masyarakat (Sumaatmadja,1981:125-126). Berdasarkan penjabaran tersebut maka lokasi kegiatan yang melayani kebutuhan penduduk itu harus ada pada tempat yang sentral.

Penentuan rute optimal dari atau menuju rumah sakit membutuhkan analisis spasial. Analisis ini digunakan sebagai cara untuk menjelaskan mengenai pola jaringan transportasi. Akan tetapi, keterbatasan visual dari mengamati pola pencarian rute mengakibatkan lambanya penerimaan informasi (Budiyanto, 2004:95). Persoalan ini dapat terjawab dengan menggunakan kemampuan Sistem Informasi Geografi. Kemampuan SIG dapat dilihat dari menjawab pertanyaan- pertanyaan yang bersifat konseptual seperti what is at? where is it? 
What has changed since? What spatial patterns exist? What if? (Prahasta 2001:71). Oleh sebab itu, berdasarkan fenomena tersebut, maka dilakukan penelitian dengan Judul "Rute Optimal Kendaraan Bermotor Berdasarkan Keterjangkauan Rumah Sakit Umum Di Kota Yogyakarta".

\section{METODE}

Metode penelitian ini menggunakan metode deskriptif kuantitatif. Metode ini digunakan untuk melihat rute optimal kendaraan bermotor dan cakupan dari keterjangkauan yang dimiliki oleh rumah sakit-rumah sakit di Kota Yogyakarta. Penelitian ini merupakan penelitian survei dengan menggunakan metode deskriptif dengan analisis kuantitatif. Data yang diperoleh kemudian diolah dan sajikan dalam bentuk peta. Survei dalam penelitian ini dilakukan untuk mengetahui titik kemacetan, Traffic light, jalan searah, jalan dua arah dalam menghadapi hambatan terhadap akses jalan, sedangkan deskriptif digunakan untuk menjelaskan mengenai hasil survei yang dilakukan sehingga diketahui keterjangkauan rumah sakit.

Analisis SIG digunakan untuk mendapatkan informasi berupa rute optimal yang harus dilalui untuk dapat mencapai rumah sakit. Penggunaan SIG dianggap lebih dapat menjawab permasalahan spasial secara efektif dan konseptual (Prahasta 2001:71). Pengolahan data yang digunakan dalam penelitian ini menggunakan network analysis. Pemilihan network analysis dilakukan karena memiliki sub- analisis spasial berupa pemodelan jaringan (ESRI, 2012).

\section{HASIL DAN PEMBAHASAN \\ Daerah Penelitian}

Kota Yogyakarta terletak di wilayah adminsitratif Provinsi Daerah Istimewa Yogyakarta (Gambar 1) . Kota Yogyakarta secara astronomis terletak antara 110 $24^{\prime} 19^{\prime \prime}$ -

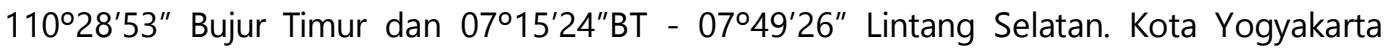
memiliki luas wilayah $32,5 \mathrm{Km}^{2}$ atau $1,02 \%$ dari luas wilayah Provinsi Daerah Istimewa Yoogyakarta. Jarak terjauh daru Utara ke Selatan kurang lebih 7,5 Km dan dari Barat ke Timur kurang lebih 5,6 Km Secara administratif Kota Yogyakarta terdiri dari 14 kecamatan, 45 kelurahan, 617 RW dan 2532 RT.

Kota Yogyakarta yang terletak di daerah dataran lereng aliran Gunung Merapi memiliki kemiringan lahan yang relatif datar antara $0-2 \%$ dan berada pada ketinggian rata-rata 114 meter dari permukaan air laut (dpal). Sebagian wilayah Kota Yogyakarta dengan luas 1.657 hektar terletak pada ketinggian kurang dari 100 meter dan sisanya 1.593 hektar berada pada ketinggian antara 100 hingga 199 meter dari permukaan air laut (BPS, 2014).

Penggunaan lahan di Kota Yogyakarta dibedakan menjadi dua, yaitu lahan sawah dan lahan bukan sawah. Lahan bukan sawah meliputi lahan untuk bangunan dan sekitarnya, tegal/kebun, ladang/huma, tambak, kolam/ tebat/ empang, lahan yang sementara tidak diusahakan. Pada tahun 2014 luas lahan di Kota Yogyakarta tercatat 3.250 hektar, terdiri dari 65 hektar lahan sawah dan 3.185 hektar lahan bukan sawah (BPS, 2014). 


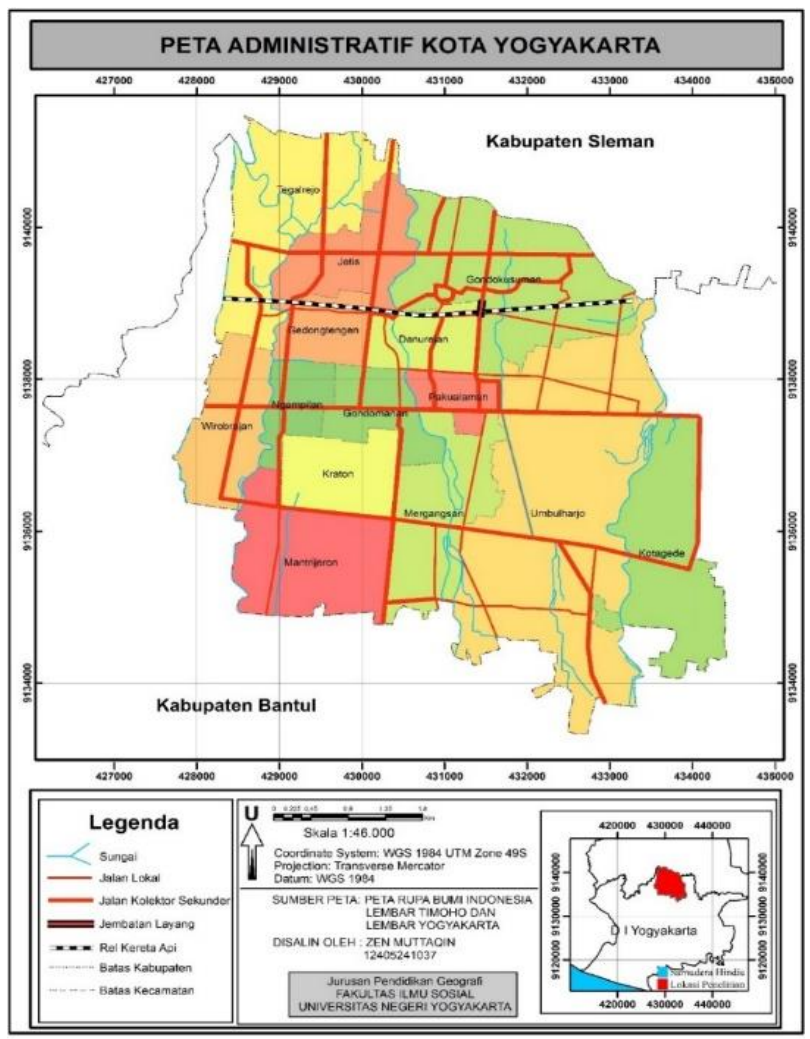

Gambar 1. Peta administratif Kota Yogyakarta

Berdasarkan sensus penduduk tahun 2014, jumlah penduduk Kota Yogyakarta berjumlah 400.467 jiwa dengan rincian sebanyak 194.828 jiwa penduduk laki-laki dan 205.639 jiwa penduduk perempuan. Sedangkan kepadatan penduduknya tahun 2014 sebesar 12.322 jiwa per $\mathrm{km}^{2}$. Kepadatan penduduk di Kota Yogyakarta setiap Kecamatan tahun 2014 dapat dilihat pada Tabel 1.

Tabel 1. Kepadatan Penduduk Kota Yogyakarta Tahun 2014

\begin{tabular}{|l|l|c|c|c|c|}
\hline No & Kecamatan & $\begin{array}{l}\text { Luas } \\
\left(\mathrm{km}^{2}\right)\end{array}$ & $\begin{array}{l}\text { Jumlah } \\
\text { Penduduk (jiwa) }\end{array}$ & $\begin{array}{l}\text { Kepadatan } \\
\left.\text { Penduduk (jiwa/km }{ }^{2}\right)\end{array}$ & $\%$ \\
\hline 1. & Mantrijeron & 2.61 & 31.901 & 12.223 & 99,20 \\
\hline 2. & Kraton & 1.40 & 17.217 & 12.298 & 99,81 \\
\hline 3. & Mergangsan & 2.31 & 29.537 & 10.225 & 103,77 \\
\hline 4. & Umbulharjo & 8.12 & 83.031 & 11.013 & 82,98 \\
\hline 5. & Kotagede & 3.07 & 33.811 & 11.453 & 99,38 \\
\hline 6. & Gondokusuman & 3.99 & 45.697 & 16.776 & 136,15 \\
\hline 7. & Danurejan & 1.10 & 18.454 & 14.546 & 118,05 \\
\hline 8. & Pakualaman & 0.63 & 9.164 & 11.760 & 95,44 \\
\hline 9. & Gondomanan & 1.12 & 13.171 & 20.035 & 162,60 \\
\hline 10. & Ngampilan & 0.82 & 16.429 & 14.227 & 115,46 \\
\hline 11. & Wirobrajan & 1.76 & 25.039 & 18.280 & 148,35 \\
\hline 12. & Gedongtengen & 0.96 & 17.549 & 13.724 & 111,38 \\
\hline 13. & Jetis & 1.70 & 23.331 & 12.418 & 100,78 \\
\hline 14. & Tegalrejo & 2.91 & 36.136 & 12.322 & \\
\hline & Kota Yogyakarta & 32.50 & 400.467 & & \\
\hline
\end{tabular}

Sumber: (BPS, 2015) 


\section{Identifikasi Keterjangkauan Rumah Sakit Umum di Kota Yogyakarta}

Penentuan standar minimal pelayanan kesehatan didasarkan pada Keputusan Menteri Permukiman dan Prasarana Wilayah No.534/KPTS/M /2001. Terlihat pada Tabel 2 adalah jumlah tingkat daya layan dari fasilitas kesehatan.

Tabel 2 Pedoman Penentuan Standar Pelayanan Minimal Sarana Pelayanan Kesehatan

\begin{tabular}{|c|c|c|c|c|}
\hline \multirow[b]{2}{*}{ No } & \multirow[b]{2}{*}{ Jenis Sarana } & \multicolumn{2}{|c|}{ Standar Pelayanan } & \multirow[b]{2}{*}{ Kriteria } \\
\hline & & Cakupan & $\begin{array}{l}\text { Tingkat } \\
\text { Pelayanan } \\
\text { (jiwa) }\end{array}$ & \\
\hline 1. & Balai Pengobatan & \multirow{6}{*}{$\begin{array}{l}\text { Satuan wilayah } \\
\text { Kabupaten / Kota }\end{array}$} & 1.250 & \multirow{6}{*}{$\begin{array}{l}\text { Lokasi dipusat } \\
\text { lingkungan, bersih, } \\
\text { mudah dicapai, tenang, } \\
\text { jauh dari sumber } \\
\text { penyakit, sumber bau } \\
\text { sampah, dan } \\
\text { pencemaran lainnya. }\end{array}$} \\
\hline 2. & Klinik Bersalin & & 30.000 & \\
\hline 3. & Puskesmas & & 120.000 & \\
\hline 4. & Tempat Praktek Dokter & & 5.000 & \\
\hline 5. & Apotek & & 30.000 & \\
\hline 6. & Rumah Sakit & & 240.000 & \\
\hline & $\begin{array}{l}\text { mber: Keputusan } \\
.534 / \text { KPTS/M/2001 }\end{array}$ & Menteri & $\operatorname{lan}$ & Prasarana \\
\hline
\end{tabular}

Berdasarkan ketentuan pada Kepmen Permukiman dan Prasarana Wilayah No. 534/KPTS/M/2001 menyebutkan bahwa standar pelayanan minimal fasilitas kesehatan rumah sakit di perkotaan berada pada cakupan satuan wilayah kota dengan 240.000 jiwa per satu rumah sakit. Jumlah pada ketentuan standar pelayanan minimum (SPM) ini tidak sesuai jika diterapkan pada Kota Yogyakarta.

Penjelasan dari Teori Christaller mengenai tempat sentral (Gambar 2), keberadaan fasilitas dipengaruhi oleh threshold dan range, akan tetapi jarak antar range pada pusatpusat pelayanan membentuk bagian yang saling bersinggungan. Mengantisipasi perebutan wilayah ditarik garis lurus sehingga membentuk bagian heksagonal. Bagianbagian heksagonal ini perlu memiliki penghubung agar dapat menjangkau masing-masing pusat pelayanan (Gambar 3)

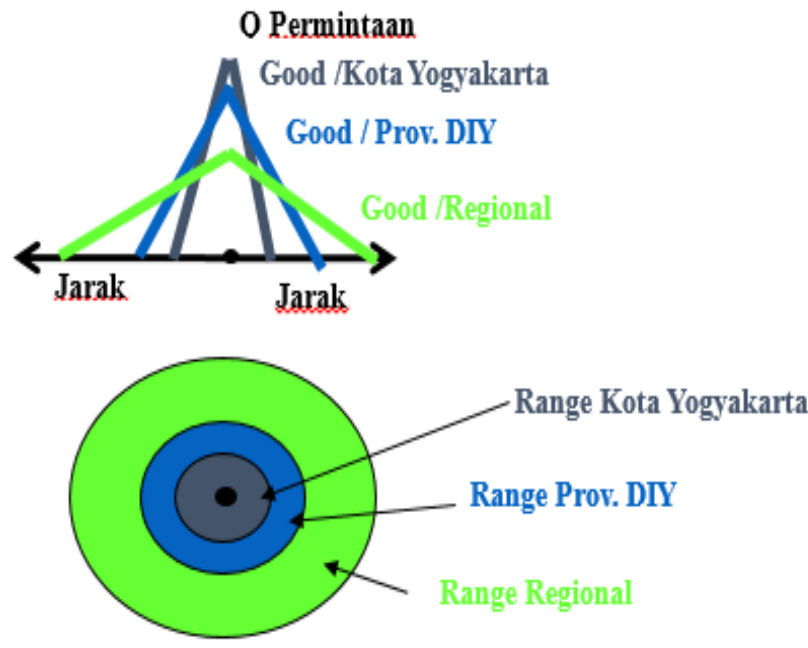

Gambar 2. Pembagian Region Pusat Pelayanan 


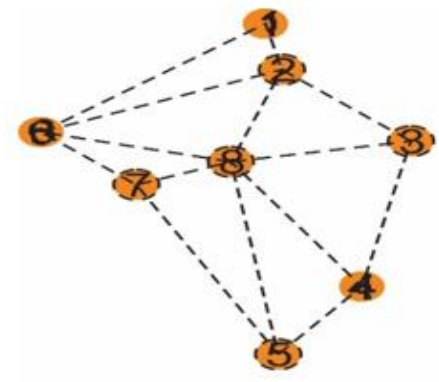

(A)

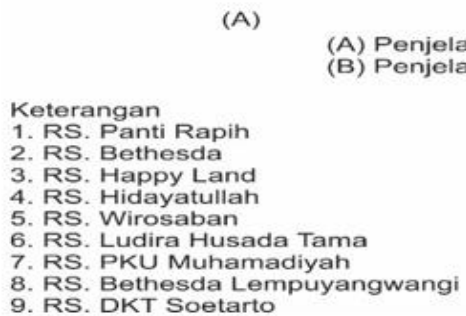

(A) Penjelasan mengenai Teori K-3

3. RS. Bethesda

4. RS. Hiday

7. RS. PKU Muhamadiyah

Lempuyangwang

\section{Gambar 3. Visualisasi Teori Cristaller}

Berdasarkan Gambar 3 dapat diketahui bahwa jangkauan dari masing-masing penarik garis digunakan untuk memperjelas teori $k-3$. Penghubung garis inilah yang nantinya akan menentukan rute manakah yang bisa dilalui. Penghubung garis antar range menggunakan keberadaan k-4 sebagai bentuk pembaharuan dan kritik terhadap teori k-3.

\section{Rute Optimal untuk Menuju Rumah Sakit Umum di Kota Yogyakarta}

Rute optimal ditentukan berdasarkan asumsi keberadaan masyarakat, karakteristik lalu lintas yang meliputi jarak tempuh, waktu tempuh dan kecepatan kendaraan, dan karakteristik hambatan yang kemudian dianalisis dengan network analysis. Berkaitan dengan asumsi keberadaan masyarakat, asumsi penentuan titik keberadaan masyarakat di kantor kecamatan didasarkan pada Undang-Undang 23 tahun 2014 tentang Pemerintahan Daerah bahwa kecamatan merupakan perangkat daerah Kabupaten/Kota dalam rangka meningkatkan koordinasi penyelenggaraan pemerintahan, pelayanan publik, dan pemberdayaan masyarakat desa atau kelurahan. Unit analisis dari penelitian ini adalah kecamatan. Area permukiman di Kota Yogyakarta berpola mengelompok pada pusat kegiatan dan tersebar merata. Hal ini disebabkan oleh kondisi geografis Kota Yogyakarta yang berada pada plain area. Kondisi inilah yang kemudian dimanfaatkan sebagai asumsi pemodelan network analysis.

Jarak tempuh dapat diartikan sebagai jarak atau panjang dari perjalanan yang ditempuh. Jalan yang berada di Kota Yogyakarta merupakan jalan umum yang terdiri dari jalan lokal dan jalan kolektor sekunder. Jalan umum menurut Peraturan Pemerintah Republik Indonesia Nomor 34 Tahun 2006 merupakan jalan yang diperuntukan bagi lalu lintas umum. Menurut keputusan Walikota Yogyakarta nomor 356 tahun 2010 tentang penetapan ruas-ruas 
jalan menurut statusnya sebagai jalan kota Yogyakarta, bahwa terdapat 411 ruas jalan yang terdiri dari 43 ruas jalan kolektor sekunder dan 368 ruas jalan lokal.

Beberapa hal dapat mempengaruhi kondisi waktu tempuh dan kecepatan kendaraan. Pertama kecepatan kendaraan dipengaruhi oleh kondisi jalan seperti kepadatan kendaraan lain. Gambar 4 menunjukkan perbedaan kondisi kepadatan kendaraan berpengaruh pada kecepatan rata-rata yang digunakan. Gambar A terlihat jalan tanpa hambatan sehingga kecepatan rata-rata yang dapat digunakan $60-70 \mathrm{~km} / \mathrm{jam}$. Gambar B adalah kondisi jalan normal. Kondisi jalan normal adalah kondisi jalan dimana lalu lintas tidak padat dan tidak terjadi penumpukan. Kondisi jalan normal kecepatan rata-rata yang digunakan berkisar 50 - 60 km/jam. Gambar C berada dalam kondisi padat, kecepatan kendaran hanya berkisar $30-40 \mathrm{~km} / \mathrm{jam}$. Kondisi padat kendaraan terjadi akibat penumpukan jumlah kendaraan dan kondisi jalan yang tidak optimal.

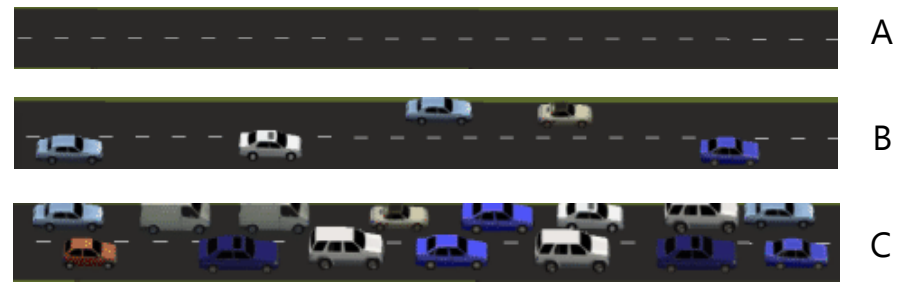

Gambar 4. Kondisi lalu lintas jalan raya

Pembagian waktu normal, sibuk, dan senggang didapatkan dari observasi lapangan yang dilakukan selama sepekan. Hasil observasi lapangan menunjukan pada pukul $22.00-$ 05.00 WIB dikategorikan waktu senggang dengan skor 1. Skor satu ini didapatkan karena pada waktu ini tidak ada kegiatan yang dilakukan masyarakat, sehingga kondisi lalu lintas dianggap kosong. Waktu normal terbagi antara pukul 09.00 - 14.00 dan 19.00-21.00 WIB. Waktu normal terjadi karena pada waktu ini masyarakat melakukan kegiatan sesuai kapasitasnya masing-masing. Pukul 12.00-13.00 WIB terjadi peningkatan kesibukan disebabkan karena pada pukul 12.00-13.00 terdapat jam istirahat dari para pekerja, sehingga ritme lalu lintas menjadi lebih sibuk dibandingkan dengan jam normal. Jam sibuk terjadi pada pukul 06.00-09.00 dan 15.00-18.00. Terjadinya jam sibuk disebabkan pada pukul 06.00-09.00 masyarakat berangkat melakukan kegiatan seperti ke sekolah dan ke kantor. Pukul 16.00-18.00 terjadi peningkatan lalu lintas disebabkan jam pulang kantor. Berdasarkan data tersebut, maka kepadatan lalu lintas berpengaruh pada kecepatan dan waktu tempuh kendaraan. Semakin padatnya lalu lintas maka kecepatan yang ditempuh akan semakin kecil dan waktu tempuhnya menjadi lebih lama.

Perhitungan rute optimal dipengaruhi oleh keberadaan Traffic light, semakin banyak Traffic light yang dilalui maka waktu yang dihasilkan untuk mencapai rute menuju rumah sakit akan semakin lama. Sebagai contoh rute yang dilalui dari kecamatan Mantrijeron menuju rumah sakit Wirosaban dengan melewati 3 Traffic light. Rute tersebut seharusnya dengan jarak $2219.6 \mathrm{~m}$ dapat ditempuh dengan kecepatan rata-rata $50 \mathrm{~km} / \mathrm{jam}$ selama 3 menit. Hambatan lalu lintas berupa Traffic light diperhitungkan maka waktu tempuh akan bertambah seiring dengan banyaknya Traffic light. Selain traffic light, hambatan lalu lintas 
berupa jalan searah dan perlintasan rel kereta api. Jumlah jalan satu arah ini dapat berubahubah sesuai dengan kebijakan lalu lintas. Evaluasi rekayasa lalu lintas selalu dilakukan untuk melihat efektivitas rute yang dihasilkan.

Penentuan rute optimal diperoleh menggunakan aplikasi ArcMap dengan bantuan network analysis. Batas kecepatan pada penelitian ini diasumsikan dengan 50 km/jam karena menurut peraturan menteri perhubungan Republik Indonesia nomor 111 tahun 2015 tentang tata cara penetapan batas kecepatan bahwa batas kecepatan paling tinggi untuk kawasan perkotaan adalah 50 kilometer per jam. Hasil dari masing-masing rute dan waktu tempu pada masing-masing rumah sakit dapat dilihat pada Tabel 3.

Tabel 3. Perhitungan rute optimal masing-masing kecamatan.

\begin{tabular}{|l|l|l|l|l|l|}
\hline NO & Kecamatan & Rumah Sakit & $\begin{array}{l}\text { Jarak } \\
\text { Tempuh } \\
\text { (meter) }\end{array}$ & $\begin{array}{l}\text { Waktu } \\
\text { Tempuh } \\
\text { (Menit) }\end{array}$ & $\begin{array}{l}\text { Waktu Tempuh } \\
\text { dan Hambatan } \\
\text { sesuai kondisi } \\
\text { lapangan }\end{array}$ \\
\hline 1 & Wirobrajan & Ludira Husada Tama & 2072 & 2 & 5 menit 12 detik \\
\hline 2 & Ngampilan & PKU Muhammadiyah & 1360.2 & 2 & 3 menit 6 detik \\
\hline 3 & Kraton & PKU Muhammadiyah & 833 & $<1$ & 1 menit 42 detik \\
\hline 4 & Gondomanan & PKU Muhammadiyah & 504 & $<1$ & 1 menit 31 detik \\
\hline 5 & Mergangsan & Wirosaban & 1382.5 & 2 & 5 menit 28 detik \\
\hline 6 & Pakualaman & $\begin{array}{l}\text { Bethesda } \\
\text { Lempuyangwangi }\end{array}$ & 1392.4 & 2 & 5 menit 55 detik \\
\hline 7 & Danurejan & $\begin{array}{l}\text { Bethesda } \\
\text { Lempuyangwangi }\end{array}$ & 218.1 & $<1$ & 40 detik \\
\hline 8 & Gedongtengen & Ludira Husada Tama & 876.3 & 1 & 3 menit 22 detik \\
\hline 9 & Tegalrejo & Ludira Husada Tama & 1707.3 & 2 & 4 menit 32 detik \\
\hline 10 & Jetis & Ludira Husada Tama & 1719 & 2 & 5 menit 28 detik \\
\hline 11 & Gondokusuman & Happy Land & 1527 & 2 & 6 menit 25 detik \\
\hline 12 & Umbulharjo & Hidayatullah & 816 & $<1$ & 1 menit 41 detik \\
\hline 13 & Kotagede & Hidayatullah & 1392 & 2 & 4 menit 15 detik \\
\hline 14 & Mantrijeron & Wirosaban & 2219 & 3 & 11 menit 46 detik \\
\hline
\end{tabular}

Sumber: Hasil Olahan Data, 2016

Rute tercepat berada pada Kecamatan Danurejan menuju Rumah Sakit Bethesda Lempuyangwangi. Rute ini hanya menempuh jarak 218 meter dengan waktu tempuh 40 detik. Cepatnya rute yang dilalui disebabkan lokasi rumah sakit yang masih dalam lingkup satu kecamatan dan tidak melewati hambatan. Sedangkan rute terlama terlihat pada Kecamatan Mantrijeron menuju Rumah Sakit Wirosaban. Lamanya rute yang dilalui karena banyaknya hambatan dan jarak tempuh yang relatif panjang. Penentuan rute optimal menuju rumah sakit tidak hanya disajikan dalam Tabel 3 namun juga dilengkapi dengan rute mana saja yang harus dilalui. Direction atau arahan rute optimal diperlukan agar pengguna tidak bingung melewati jalan mana yang harus ditempuh agar sampai di rumah sakit. Gambar 5 berikut ini menunjukkan peta rute optimal kendaraan bermotor menuju rumah sakit. 


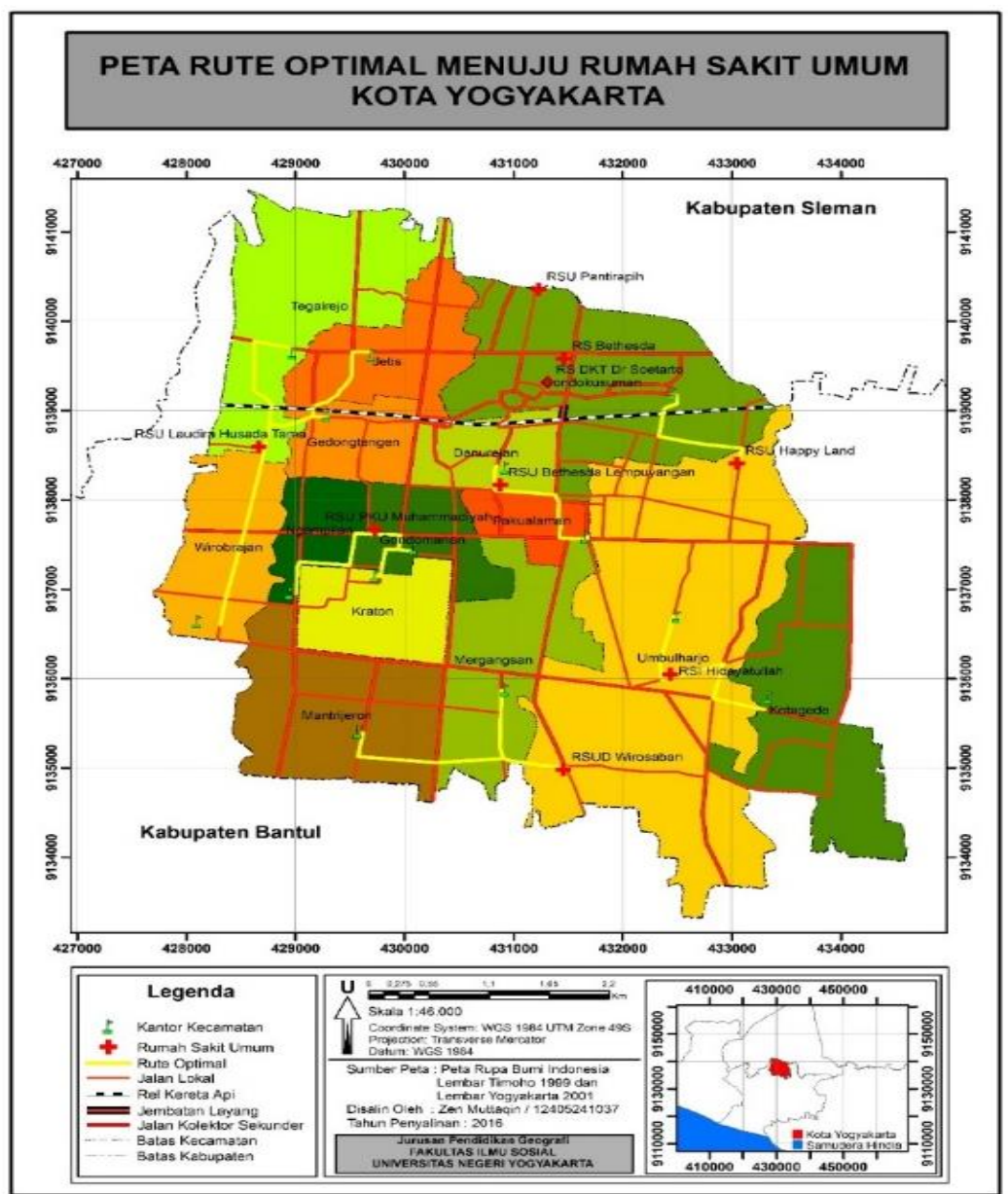

Gambar 5. Rute Optimal Menuju Rumah Sakit Umum Kota Yogyakarta

\section{SIMPULAN}

Berdasarkan kriteria daya layan fasilitas pelayanan kesehatan dan teori Christaller diketahui bahwa keterjangkauan rumah sakit di Kota Yogyakarta berbeda-beda. RS Ludira Husada Tama dapat menjangkau wilayah Kecamatan Wirobrajan, Jetis, Tegalrejo, Gedongtengen. RS PKU Muhammadiyah dapat menjangkau wilayah Kecamatan Ngampilan, Gondomanan, Kraton. RS Bethesda Lempuyangwangi dapat menjangkau wilayah Kecamatan Danurejan dan Pakualaman. RS Happy Land dapat menjangkau wilayah Kecamatan Gondokusuman. RSI Hidayatullah dapat menjangkau wilayah Kecamatan Umbulharjo dan Kotagede. Rumah sakit RSUD Wirosaban dapat menjangkau wilayah Kecamatan Mergangsan dan Mantrijeron. Hal ini berimplikasi pada seluruh masyarakat dapat melakukan akses terhadap pelayanan tanpa dibatasi oleh keterjangkauan dari rumah sakit. Rute optimal antara kecamatan dengan rumah sakit juga bervariasi tergantung pada jumlah hambatan, panjang jalan, dan kepadatan lalu lintas yang dilalui. 


\section{UCAPAN TERIMA KASIH}

Tulisan ini merupakan bagian dari penelitian tugas akhir skripsi yang berjudul Rute Optimal Kendaraan Bermotor Berdasarkan Keterjangkauan Rumah Sakit Umum Di Kota Yogyakarta. Dalam kesempatan ini penulis mengucapkan terima kasih yang sebesarbesarnya kepada berbagai pihak yang telah membantu dalam proses penelitian, khususnya kepada pembimbing tugas akhir.

\section{DAFTAR PUSTAKA}

Adisasmita, S. A. 2011. Transportasi dan Pengembangan Wilayah. Yogyakarta: Graha Ilmu. BPS. 2014. Daerah Istimewa Yogyakarta Dalam Angka Tahun 2014.

Budiyanto, E. 2004. Sistem Informasi Geografis Menggunakan Mapinfo. Yogyakarta: Andi. Keputusan Walikota Yogyakarta Nomor 356//KEP/2010 Tentang Penetapan Ruas-Ruas Jalan Menurut Statusnya Sebagai Jalan Kota Yogyakarta.

Prahasta, E. 2001. Konsep-Konsep Dasar Sistem Informasi Geografis. Bandung: Informatika. Sumaatmadja, N. 1988. Studi Geografi Suatu Pendekatan Dan Analisa Keruangan. Bandung: PT. Alumni. 